\title{
28 tcect.
}

Die bon ber \$reupifकen Gejęgebung firitten Rebts. normen laffen fidh nad ibrer Quelle in zroei Şauptllaffen \{deiben, je nadbem fie fid auf Erfahrung grünben ober nidtt. Die ber legtern $x_{\text {rt }}$ jino jolde Săke, bei welden man abfidtlid ben biftorilden soben bat berlaffen, uno etwas Bernunftgemäßeres obet anjđeineno Befferes an bie Stelle bes Bisherigen bat feken wollen. Sie gleiden spfropfreifern, unb finb theils berbort, theils mit igrem Stanm verwadfen. Das lektere ift mit aller folden Gäken ber fall, welde mit bem WBefen bes Jnflituts im 2uggemeinen harmoniren, unb entweber eine glüđlide Fortbilbung, ober eine, bem practifめen \$Bebürfnis ents fpredenbe, umgeftaltung beffelben berwirtt baben. Diefe geben baburd in bas hifforifde Redtstgebiet über.

Die Beftimmungen ber bei weitem überwiegenben orweiten Scauptłlaffe finb hauptjädlid aus ber bamaligen ODrariš entnommen. Die গgraris grünbete fid theils auf

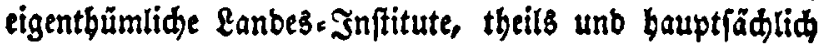
auf bas gemeine Piecht. Die Suelle biefes Rectis ift, weil ts eine allgemeine Beféggebung nidt giebt, bie $\mathbb{K B i}$. fenfकaft, unb biefe eridheint äußerlid in ben Suriften, unb vorzugstweife in beren wiffemihaftliden \&eiftungen, rooju aud bie Partilłulargefeggebungen cinzelner Länber, als Probucte ber wiffenfdaftliden sibătigleit ihrer Rebacto.

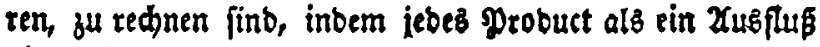
biefer Quelle zu betradten if *). Daraus folgt, bas bie

-) Bergl. Beorge Friedr. Pu由ta: Heber eine Pecenfion ron Sapigny's Gefdidte bes Romifaen Redts im gRittrm 
Senntni $\bar{\beta}$ ber Ritetåt: und ber Dogmen. (Se[did)te bes gemeinein Rechts eine Bebingung zur grünbliden Bebant.

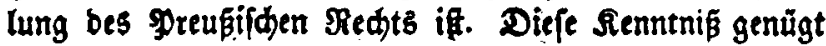

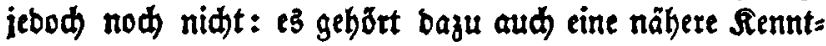

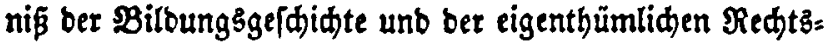
anfidten ber einzelnen Mitarbeiter an ber Febaction ber

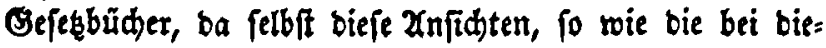
per Xrbeit gebraudten Sdriften, als Duelle ber Befess= gebung angefehen merben fönnen ${ }^{*}$ ). Die befte Bearbei=

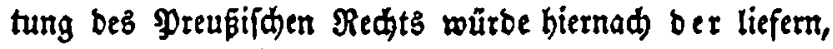
weld)er bie Riterär = unb Dogmen=(Sefdidte völlig in fei= ner Gerwalt bat, bie Biographien und Meinungen ber Resactoren ber Gefegbüber, befonbers der bes augem. Zanbredbts, genau tennt, unb bie von ihnen gebraudten Şilfşwerfe vor fid bat. WBie mübfam bas Stubium bie: fer Quetlen ift, zeigt fid son felbft. 2(ber nidt blos müb= fam, fonbern aud fdrwierig unb theilmeife unmöglid ift baffelbe wegen bes sangels ber bazu erforbetliden lite: ratifhen Mittel. Der Drud ber Materinlien ber Gejeks=

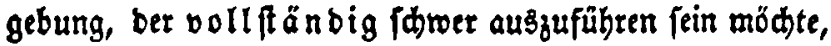
würbe bemfelben fwar immer nur fum ITheil abhelfen, aber boh) eine grofe \&üđe ausfülten, unt ben 2(pparat bebeuteno vermehren. Die bloße Einfidit ber Materialien von Einzelnen ift ein ungenưgenbes uno unzuverläsigigę Surrogat ber Beröffentlidung berferben. Eine vielleidt febr mâhjame, aber für bie wiffenidaftlide Behanblung

alter, in ben Berliner Jabrbüdern für mifienfdaftlide

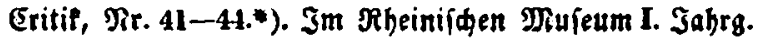
IV. Seft S. 334.

-) In den Diotiven der Beíetz:Mevifion, Penínm XII. S. 117 beift es: "- Das gllgem. Santredt, weldes wir rod, bis auf einzelne \$usnahmen, für nimts anters, als ein niedergejdriebenes, oamals gel tendes Redt, anfehen tönnen -". Dief wiro von Len Prattitern viel ju we: nis erfanut. 
tab Yreukijhen Redts außerorbentlid frudtbare Xrbeit

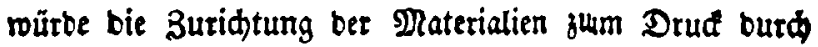
einen Eadoerfändigen fein, welder mit fiderer Stand bas nur (d)einbar unwidtige von bem wirklid) unwidtigen faiebe.

Eine volftänbige quellenmäßige Bearbeitung bes

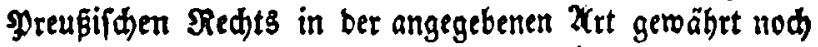
einen practijhen Bortheil: fie ffeltt bie abgefonittene Berbinbung bes Preußs. Redtz von ber gemeinredttiden Eiteratur wicber ber; fie bebt bie Irennung eines Brweis ges von feinem Stamme auf, bei weld)er ber Bweig utrs

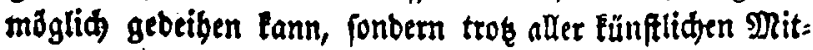
tel abwelken muk, wenn er nidst in einen, feiner Ratur intipredienben Boben gepflangt uns gepflegt wirb; furs, fie faliest bem Ptactiler ben Sd)a taulentiäbriges, burd ben geübteften Sdjarffinn erprobter, uno burdh viel: faden Bebraud bemährter Erfahrungen auf, reldhe man jegt wie abgemuktes, für ben beutigen Rechtszuftano un= braudbar getoorbenes, altes Getäth anzulften gewobnt ift. Rad) biejer Boraus/egung ergiebt fid win folbft, Daf bie Madweifung bes Bufammenhangs bez heutigen Redts mit ber früheten Şraris eine Şauptaufgabe ber von bem Berfaffer iuntemommenen Xrbeit if. Es ver=

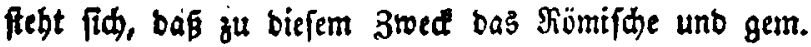
Redt nidt Gegenftand einet unterfuct)ung iff, fonbern

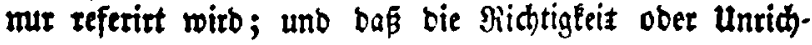
tigteit cingelner Meinungen Rebenfade ift. 2(ud) unrid. tige Meinunger fino, in fofern fie auf bie Mreupifde

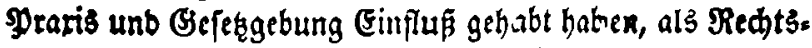
quelle anzufeben, uno bie 2rufgabe bei bieren beftegt nidht barin, bie Unridtigleit zu bem 3med zu zeigen, um zu beweifen, baß bie geétglidge Beftimmung in ben preus.

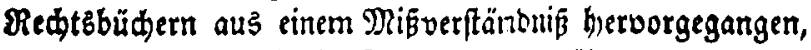
unb bas fie beshalb abgeftellt werben muffe; fonbern fit 
befteht vielmehr barin, bie Brünbe biefer, wettrgleid uns ridtigen Deinung - zu unterfucen unb anzugeben, um Diefelben bei ber reitem Xubbilbung ber baburd gerwor. nenen Xnfidt, unb jut Erflärung ber baraus entftanbes nen gefegliden Norm zu benuken. Şiernad ift bie fris

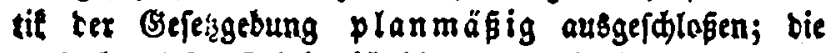
Xufgabe siefer Sadrift ift blop: bas wirtlid Borbanbene

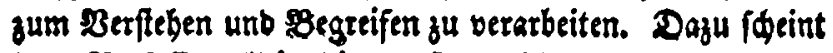
bem Berfaffer allein bie gewählte bifforifde Inetbobe ge. rignet, weil ein nadfolgender 3uftano nidt ridtig er. fannt werben tann, wenn ber Borbergebente nidit belannt ift, und ba ber vorlandrehtlide Redtbojuftand als bie Shauptquelle bes jekigen $R e d t$ to anjujehen ift, fo redtter, tigt fid bie etwas fpecielle $B$ Bhandlung bes gemeinen

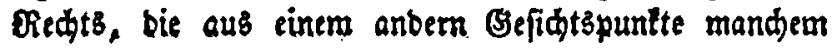
bielleidy zu ausffübrlid foreinen tönnte, von felbft. Die Xrbeit muß als ber 2 nfang einer Brüde angejeben mers ben, welde nothwendig zwi joen ber alten gemeinredtlis ben, uno ber neuen Mreufifiden Riteratur aufzubauen if. Die 20jidt bes setfaffers ift erteidt, menn biefe müb/ame Zrbeit nur ber Metbobe Xnbänger verfádafit;

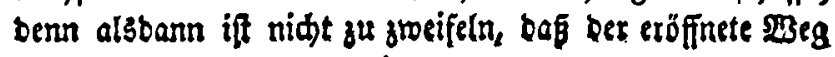
weiter bre eten werben wirb.

Das garte Dbligationentedit fot in brei Dctab. bänoen bargeftellt werten. Der erfere Banb, welder bie beiben erften Sapital bes allgemeinen Ilbeils enthält, wurb bem juriftifden \$oblico jest übergeben. Dex jweite welder ben allgemeinen abeik beidliegt, foll, fobalo es

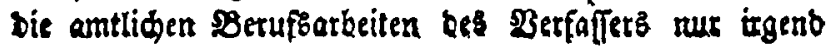
geftatten, nadfolgen.

Eepdrieten zu Eibe Iuni 1835. 